\title{
Challenges of Post-Surgery Recovery and Rehabilitation
}

\section{Anil D Kulkarni*}

Department of Surgery, University of Texas Medical School, USA

\section{Introduction}

Surgery is one of the most ancient medical specialties that deals with operative procedures and instrumental techniques for treatment or investigation of pathological conditions for improving bodily functions or appearance. Currently many of the deadly diseases fall into surgical treatment category and need to be operated. Surgery: Current Research is an international peer-reviewed open access Journal that publishes scientific articles related to all the aspects of surgery such as manual operations, surgical techniques, advanced instrumental techniques to cure pathological conditions such as burn, injury or disease. The current Volume 6 issue 3 carries one research article, a review article and two case reports.

Said et al. investigated the metabolic changes in patients after Laparoscopic Sleeve Gastrectomy (LSG). Their studies concluded that LSG is an effective bariatric procedure for losing weight and in correcting metabolic disturbances associated with obesity due to type 2 diabetes [1]. Hattarki et al. compared the functional outcomes of distal metaphyseal fractures of tibia treated by plating with reamed intramedullary nailing and complications arising with different modalities of fixation [2].
Chaudhary et al. reported the case of acute appendicitis caused by pin worm in 11 year old female [3]. Kiuchi et al. in their studies concluded that renal sympathetic denervation (RSD) is effective in controlling diastolic blood pressure and pulmonary vein reisolation (PVRI) reduces volume of left atrium [4].

\section{References}

1. Said TM, Sabry K, Eweida GH (2016) Early Metabolic Outcome After Laparoscopic Sleeve Gastrectomy in Morbid Obese Patients. Surgery Curr Res 6: 266.

2. Hattarki R, Bhagat S, Patel K, Singh B, Mehendiratta D, et al. (2016) Comparative Study Between Intramedulary Interlock Nailing and Plating in Distal Metaphyseal Fractures of Tibia. Surgery Curr Res 6: 267.

3. Chaudhary R, Shukla A, Sharma K, Gupta A, Bansal M, et al. (2016) Pin Worm Causing Acute Appendicitis: Case Report. Surgery Curr Res 6: 265.

4. Kiuchi MG, da Silva GR, Paz LMR, Sauto GLL (2016) Case Report: Renal Sympathetic Denervation + Pulmonary Vein Re-isolation in Patients with Longstand Persistent Atrial Fibrillation and Resistant Hypertension. Does it Work? Surgery Curr Res 6: 268.
*Corresponding author: Anil D Kulkarni, Department of Surgery, University of Texas Medical School, USA, Tel: 713-500-7303; E-mail: Anil.D.Kulkarni@uth.tmc. edu

Received May 03, 2016; Accepted May 08, 2016; Published May 14, 2016

Citation: Kulkarni AD (2016) Challenges of Post-Surgery Recovery and Rehabilitation. Surgery Curr Res 6: e120. doi: 10.4172/2161-1076.1000e120

Copyright: ( 2016 Kulkarni AD. This is an open-access article distributed under the terms of the Creative Commons Attribution License, which permits unrestricted use, distribution, and reproduction in any medium, provided the original author and source are credited. 